\title{
Trust-Building and Social Support in the Online Social Movement Among Victims of Sexual Violence
}

\author{
Dinna Khairina ${ }^{1,}$ Endah Triastuti ${ }^{2 *}$
}

\author{
${ }^{1}$ Universitas Indonesia \\ ${ }^{2}$ Universitas Indonesia \\ *Corresponding author. Email: dek.titut@gmail.com
}

\begin{abstract}
This paper attempts to analyze the role of an online social media movement in obtaining social support for women victims of violence. To mobilize and run a social movement in the online world effectively, we believe that trustbuilding is needed to create collective identity and collective action and also to support the three elements of a social movement (Campaign, Repertoire, and WUNC [Worthiness, Unity, Number, and Commitment]) (Carty, 2018). In this literature review, authors use a term and a model of trust in from Lewicki and Bunker (1996) to analyze the online movement as a positive space for social support among netizens and sexual violence victims. The authors believe that the trust-building model in the virtual community can also be implemented to achieve the movement's goals and to encourage victims of sexual violence to seek support through an online social movement.
\end{abstract}

Keywords: Social Movement, Trust, Social Support, Sexual Violence, Women Against Violence

\section{INTRODUCTION}

This paper aims to understand trust-building and the role of an online movement in obtaining social support for victims of sexual violence. Previous researchers have found that social support online can provide not only positive but also negative impact. Research from Kim (2014) found that Facebook (an online medium or social networking site) is a significant source of social support for college-aged adults that contributes more to their social support than a number of strong ties (Kim, 2014). While Yeager (2012) argues that online social support has both positives and negatives, the advantages are accessibility, anonymity, support, and control. Online social support's disadvantages include lack of physicality, overwhelming content, and negative social support features (Yeager, 2012). Therefore, this paper's focus is to explore creation of positive social support online in a social movement constructed according to Lewicki and Bunker's (1996) virtual community trust model.

Historically, the various political and social turbulences in the United States and most European countries after 1960 became primary factors for sociologists' research into social movements (McAdam et al., 1988), which are efforts to change social norms, social policies, and daily behavior (Giele, 1988). The term "social movement" was first introduced by Lorenz Von Stein, a German sociologist, in History of the French Social Movement: From 1789 to the Present (1850), which initially conveyed the idea of continuity and the unity of the process by which the entire working class received self-awareness and strength (Tilly, 2004).

A ssocial movement is a collective phenomenon that appears primarily among a group of individuals sufficiently organized and equipped with resources to continue a protest campaign that unites and forms movement groups (McAdam, 1982). Social dynamics caused by groups of individuals, groups and/or organizations that interact in informal networks and are involved in a political and/or cultural conflict based on collective identity, are a process of creating social movements (Diani, 1992). According to Melucci (1989), collective identity is a "shared definition produced by several interactors" ... "the fields of opportunities and constraints in which their actions take place" (Shangapour, 2011). From this definition, we can conclude that a social movement is a collective phenomenon by groups of individuals who interact to create social dynamics as a protest against political and/or cultural conflict based on collective identity and to change social norms, social policies, and daily behavior. 
The digital age and virtual communication bring social movements into online media to protest and achieve their goals. New technological and media platforms play an important role in forming social movements and changing social movements' terrain even more radically than previous technologies (Carty, 2018). Using new communication technology is referred to as the realm of the New Social Movement to spread radical social criticism and alternative culture by providing an environment where people can gather to provide information, publish it, create dialogue and lateral relations, and coordinate actions (Shangapour, 2011). Until now, for example, the Women's Movement has participated in campaigns and movement activities in the online world, especially in social media.

One issue voiced by the Women's Movement is that of gender. In the Women's Movement, gender issues are referred to as a force in developments, emergences, and traits that pervade social movements (Taylor, 1999). Participation of female workers in the United States during World War II helped encourage the new Women's Movement in seeking female workers' improved salaries, education and employment, reproductive rights, and greater public support of equality for women's traditional activities (Giele, 1988). Long before the organized Women's Movement first began in the United States in 1848, the debate on gender equality had been voiced through Mary Wollstencraft's publication A Vindication of the Rights of Women in 1792 (Ryan, 1992).

In carrying out the Women's Movement, female activists have not striven just for patriarchal communitybased change, but also currently for developing boundaries of the localization struggle and linking them to the global struggle (Pandhe, 1988). In 1968, the term "Women's Liberation" was used by activists who understood themselves as building a movement (Evans, 2015), and it continues to be used in social movements in which women's groups are united by the same ideas and goals, for instance, building awareness of women's position of inequality with men (Doeneka, 1972).

Men's inequality with and power over women is proven, in one type of instance, by men's acts of violence against women (Walby, 1990), that is, "genderbased violence." Violence by men against women illustrates power imbalances in their relations that extend women's subordination and devaluation (Rico and United Nations, 1997). As Ellsberg and Gottemoeller (1999) state, "Specifically, violence against women includes acts of verbal or physical force, coercion or life-threatening deprivation, directed at an individual woman or girl that causes physical or psychological harm, humiliation or arbitrary deprivation of liberty and that perpetuates female subordination" (Heise et al., 2002).
Violence against women can occur in many forms, among them sexual violence (rape, sexual abuse, incest), domestic violence, human trafficking, prostitution, female infanticide, genital mutilation, and murder (Sen et al., 1998). Sexual violence against women negatively impacts their short- and long-term psychological and physical health. Various impacts on the mental health of victims of sexual violence include post-traumatic stress disorder, depression, anxiety, phobias, panic disorders, eating disorders, sexual dysfunction, low self-esteem, and substance abuse - all of which can lead eventually to sexually transmitted diseases (AIDS), death in pregnancy, suicide, and murder (Heise et al., 2002).

Communications and relationships that support and assist victims of sexual violence, needed to manage a violent situation, are referred as social support and play an important role in the physical and mental health of victims of sexual violence (Shahali et al., 2010). Although victims seem to receive less social support from non-victims, any kind of positive social support might have a protective effect on the psychological symptoms of sexual violence survivors (Mason et al., 2009).

As technology develops, it enables victims of sexual violence to seek social support in the online environment, with the Internet considered a valuable source (Kimberly et al., 2014). Online support groups without geographical limitations and with anonymity mean that victims can have unlimited communication geographically and temporally, thus minimizing their fear of stigmatization associated with their situations ( $\mathrm{Li}$ et al., 2019). Women victims of sexual violence thus have the opportunity to be revived in the community because society commonly tends to blame victims of rape and violence (Mason et al., 2009).

Victims looking for online social support have experienced receiving unfavorable, untrustworthy, and blaming treatment in their environments, but others simply claim online media support as supplementary to support from their physical environments (Yeager, 2012). Based on lack of trust by and in people around them, finally, victims seek alternative support by searching out online social support and trusting online groups.

Social movements' character as collective action enables victims to obtain social support. Trust is the element needed to create a supportive environment where victims can tell their stories and seek support. The decision to trust is influenced not only by individual objective features but also by subjective choices (Wang et al., 2018). In this case, trust can be defined as cognition that involves an emotional bond, helping someone deliberately choose trustworthy people through evidence (Barnett et al., 2010). 
To create a positive, supportive online social movement for victims of sexual violence, trust is crucial. In virtual communities, trust of groups can be achieved through a trust model that mediates the relationship between exchange phases of support, learning identity, creating identity, and encouragement with group trust as an output (Blanchard et al., 2011). This paper argues that trust involvement can be built by online social movement groups toward netizens and victims of sexual violence. Trust is a basic foundation for helping victims speak out about their experiences and gain positive social support from activists and netizens in a social movement group.

\section{LITERATURE REVIEW}

\subsection{Social Movements in Online Media}

The pervasive rise of the digital technology and social media era has impacted political debates as well as organization and participation in social movements. It has given activists access that enables innovation, helping them establish and maintain new political areas where they can discuss their complaints, disseminate information, and collectively submit their demands (Carty, 2018). Movements on social media have been implemented in various forms and at various levels to change society, eventually bringing the concept of social movements into the online world (Lopes, 2014). One online tool used by social movements is social media, which can connect people from different backgrounds globally, support movements to propagate social agendas and collective actions, and provide a forum of voices from individuals who have never before been heard.

Their geographically and temporally unlimited characteristics make social media an effective medium to implement social movement's three elements: collective action, public efforts in public space, and receiving global support and being heard by targeted authority. Carty (2018) mentions social movements' three main elements: campaign, repertoire, and WUNC (worthiness, unity, numbers, and commitment) (Carty, 2018). First, a campaign tends to be a long-term, wellorganized activity in a public effort to make a collective statement against a target authority (Carty, 2018). Second, repertoire is a series of settlement tactics owned by the group or movement in certain sociopolitical environments (Carty, 2018). Third, WUNC means that social movements are worthy of fighting for by a group with massive numbers and high commitment. Carty (2018) asserts WUNC as participants' deliberation in social movements, to present themselves and their supporters in public space as deserving of citizens' support from all around the world (Carty, 2018).

Social welfare and institutional and economic issues are some basic motives for undertaking a social movement. However, various complaints and rational ideas do not seem to be enough to make people act collectively; they also need organization, various sources (time, money, organizational capabilities, and various social and political opportunities), and communication to make social movements successful (Lopes, 2014). Today, social media means anyone can share anything, for instance, social and economic issues, that can potentially be accessed by people around the world. Social media also allow creation of collective identity, organization of ideas and, in the end, creation of a movement.

From various social movements meant to change social, political, and economic environments, researchers have isolated factors that can determine whether social movements succeed or fail (Carty, 2018). To succeed, movements must:

1. Take advantage of existing political opportunities and strategic advantages (Carty, 2018).

2. Apply various specific techniques and practices of certain organizations (Carty, 2018).

3. Elaborate clearly the movement's goals and supporters (Carty, 2018).

4. Use resources and form alliances to expand social movement support networks (Carty, 2018).

Furthermore, scholars argue that social media and information and communication technology also allow individuals to think about collective identity, in addition to disseminating information, organizing the public, and holding authorities accountable in different ways (Carty, 2018). As far as we know, collective identity is a social movement characteristic, and we can conclude that social media and information and communication technology play a leading role in today's social movements.

\subsection{Trust-Building Model and Theory in Online Social Movements}

One important component for sustaining communication, achieving movement goals, and creating a positive environment online is the trust needed to build an online community. Hill and O'Hara (2006) believe that trust is an important component of human relations and a basic building block for healthy communities (Hill and O'hara, 2006).

The trust concept has attracted attention in many scientific fields these days and produced various kinds of understanding. This actually makes use of the term "trust" and its analytical definitions confusing and sometimes inaccurate (Castelfranchi and Falcone, 2010). Scholars state that "trust is the willingness of a party (trustor) to be shown by the actions of another party (trustee) based on the expectation that the other party will take certain actions that are important to the trustor, 
regardless of the ability to monitor or control the other party" (Lauer and Deng, 2007).

Trust can also be defined at a collective or group level. Cumming and Bromiley (1996) state that group trust can (a) make good-faith efforts that apply to agreement in various commitments; (b) present honesty in any form of negotiation resulting from various commitments; and (c) prevent taking advantage of another even though the opportunity is available (Blanchard et al., 2011).

Along with these various definitions of trust, McKnight and Chervany (1996, 2001) conclude that trust includes the following three ideas (Gwebu et al., 2007).

1. Trusting belief: The extent to which someone believes in (and feels confident in this belief) and the beliefs of others in certain situations (Gwebu et al., 2007). This idea of trusting belief is one of the goals that needs to be achieved while a movement is running its sustained, well-organized campaign.

2. Trusting intention: measuring the extent to which one party tends to depend on another in certain circumstances, regardless of the possibility of negative consequences (Gwebu et al., 2007). Related to repertoire, one element in a social movement, trusting intention, can be measured as output of the repertoire element. To avoid negative consequences, several tactics need to be arranged.

3. Trusting behavior: The extent to which one party relies on the other party in a certain situation with a feeling of confidence regardless of the possibility of getting negative consequences. This idea of trust is related with the social movement element, WUNC, that is, when a number of worthy people are united in and committed to a social movement.

The online world easily provides access to publications with affordable costs and speed, a wide scope of organizational groups, and networks that connect the entire world, providing new sources of information that cannot be easily controlled by regime authority (Lopes, 2014). Thus, technology plays an important role in developing social movements because it can connect people around the world "24-7" and spread information about issues in only seconds. Not only technology, but trust plays an important role in communicating and building the community or movement through the online world. Trust can reduce transaction costs, increase comfort and security values in a relationship, encourage influential openness and substantive information exchange, and allow people to take risks (Jarvenpaa et al., 1998).

Trust can be seen from two perspectives, social and rational. From the social perspective, trust centers on moral duty, with social groups holding values about obligations to others. Rational perspectives center on calculating personal interests (Lauer and Deng, 2007). Trust can also be considered a very important socialcognitive construct. In particular, building trust is recognized as a key factor in applying and developing new interaction of paradigms (Falcone et al., 2001). So far, social media have accommodated individuals in interactions with others, and through social media, a new interaction paradigm has been formed. The fact is that each interaction requires a trust value to sustain interaction and communication, in this case, in an online social movement.

Furthermore, to recruit other people to specific goals, especially for high-risk protests, social relations, rational ties, and friendships are claimed as the right channels. Moreover, digital technology can help develop networks' potential to recruit new people by building new social networks (Carty, 2018). Scholars state that trust is an important component in virtual interactions between members of the virtual community, both socially and professionally, to preserve bonds within groups (Falcone et al., 2001).

Several types of trust can be applied to professional and personal relationships. According to Lewicki and Bunker (1996), who adapted a framework proposed by Shapiro, Sheppard, and Cheraskin (1992), the model of trust divides into three types: calculus-based trust (CBT), knowledge-based trust (KBT), and identification-based trust (IBT) (Gwebu et al., 2007). Furthermore, Gwebu, Wang, and Troutt (2007) believe that the three types of trust in traditional organizations, according to Lewicki \& Bunker (1996), have significant relevance to virtual organizations.

CBT is a prevention-based trust, based not only on fear of punishment for violations of trust but also as a reward for maintaining trust (Lewicki \& Bunker, 1996). In other words, every action, both trusting and breaking trust can provide a reward. This type of trust is fundamental for creating a movement. A person's decision to engage and survive in a trust relationship is based on rational calculation of punishments and positive rewards. Movement activists should be prepared for positive and negative engagement when they share campaign issues. They also need to estimate potential responses from social media and strategize to prevent negative responses and to maintain trust. Trustworthy and untrustworthy behaviors are formed by rewards and deterrents, and also predictable behavior (Pournaras and Lazakidou, 2008). Therefore, Gwebu, Wang, and Troutt (2007) state that activities and strategies for building trust in CBT involve formation of control and protection mechanisms that encourage mutual trust and prevent trust violations.

KBT is based on others' predictability. To some extent, people tend to depend on the predictability of the behavior of parties involved, to make rational judgments 
about whether to believe or not (Gwebu et al., 2007). In short, KBT is characterized by exchange of information (Pournaras and Lazakidou, 2008). Activists can anticipate other parties' behavior by knowing more about them and knowing that behavioral predictability can increase the level of trust. In social movements, activists need to share ideas and issues clearly and ensure that people are well informed, in order to increase people's trust in the movement. KBT emphasizes knowledge received rather than fear of punishment. Therefore, KBT becomes an important element in making judgments and determining whether trust can be built or not. To build KBT, activists need to create activities and strategies that rely on the movement's knowledge and information. Thus, for building effective KBT, activists need to highlight the normal situation and the group's belief to current and potential members (Gwebu et al., 2007). The movement needs to be transparent, that is, to share information related to the movement and the issues so that people make positive judgments, decide to trust, and stay involved.

In IBT, trust is formed because mutual understanding and appreciation are caused by certain characteristics. To fulfill requirements of trust, trust is transformed according to reliability and how reliable systems are (Pournaras and Lazakidou, 2008). At this stage, trust is built based on full internalization of the other party's desire and intention, and trust happens because each party effectively understands, agrees, empathizes, and endorses one's desire and willingness to act for the other (Lewicki and Bunker, 1996). When trust is on this level, the relationship between members in a movement group are strengthened. In a collective identity, members have the same vision and similar understanding, but can also provide each other social support. Sheppard and Tuchinsky (1996) argue that with high levels of empathy and consensus, people can effectively act together because of the belief that their own interests will fulfilled and protected. (Gwebu et al., 2007). According to Gwebu, Wang, and Troutt (2007), the thinking underlying IBT is that within groups or organizations, people tend to behave more reliably toward others in the group than toward people outside the group. After reaching the IBT level, the social movement can be an effective public place for members to seek and share social support.

According to Lazakidou (2008), CBT and KBT benefit from technology, as follows (Pournaras and Lazakidou, 2008):

1. CBT can provide advantages for predicting the scheme between organizational parties. Technology's virtual character, which does not always include face-to-face interaction, brings benefit because it is not provided positive feedback for predictions.
2. KBT is also beneficial in virtual technology because it provides so much information.

\subsection{Social Support Among Victims in Online Social Movements}

Various disciplines have conducted research on social support, evolving definitions of social support as multidimensional ideas described in multiple studies (Yeager, 2012). In general, social support is defined as a type of assistance received or expected to be received by and from individuals interconnected in any way (Papakonstantinou and Papadopoulos, 2009). OrthGomér and Undén (1987) reinforce this, defining social networking and social contact as structural aspects of social support, and available support as functional aspects of social support (Sagepub, 2014).

Social support encourages psychological well-being, self-esteem, and self-control (Papakonstantinou and Papadopoulos, 2009). Social support is also instilled in interpersonal relations as a supportive action that can protect individuals from illness and death based on stressful situations, including racial discrimination, work pressure, psychological disorders, and by having a positive effect on various events, whether they are full of pressure or not (Yang et al., 2018).

Online social support is obtained and conducted through online media. The Internet makes social support searchable, and support is provided through activities and interactions in cyberspace. Fundamental differences between traditional support groups (offline) and online support groups can be seen from their contexts: Traditional groups rely on face-to-face communication (direct), while online groups rely on textual communication mediated by computers (Yeager, 2012). An online community or support group has an important role in mental and physical health, providing online space for people to exchange aid and support through social relations and intrapersonal transactions (Chiu et al., 2006).

But in fact, online social support provides not only benefits but also losses. Yeager (2012) explains that online social support has (Yeager, 2012):

1. Advantages: Communicate anonymously 24 hours a day with people from all over the world, bringing together people with the same experience, thereby reducing risk of blame and misunderstanding.

2. Disadvantages: Unable to see visual cues, sometimes making it difficult to detect emotions and the meaning of communication; having the potential for misleading information exchange due to diversity of opinions and the speed of responding to messages.

Shumaker and Brownell (1984) define social support as "an exchange of resources at least two individuals perceived by the provider or intended to enhance the 
well-being of the recipient," so as to encourage a person's psychological and physical health (Chiu et al., 2006). Social support includes terms of received support and perceived support (Sagepub, 2014), which are not identical concepts (Yeager, 2012). Wethington and Kessler (1986) state that personal protection is reinforced by perceptions of support, and actual support is needed only when protection fails (Erol, 2008).

Perceived support is influenced by personal factors encouraging better welfare for people who experience stress in their lives (Yeager, 2012), as well as the belief that social support is needed (Sagepub, 2014), especially to restrain the effects of stress (Erol, 2008). The perceived community support dimension has a significant positive effect on community members' commitment, in which "online community members, whether they post online message or not, are considered to be perceived as being supportive of their communication as a member of the community" (Yang et al., 2016).

Received support refers to social support obtained by someone in certain situations and periods and from certain people (Sagepub, 2014). Supportive behavior (received social support) is given in stressful situations, while perceptions of social support (perceived social support) can reduce criticism so as to reduce individual stress levels (Erol, 2008).

The main objective of an online support group is to help its members overcome life stresses through social support, while perceived community privileges have a stronger effect in identifying groups than perceived external independence (Chiu et al., 2006). Women who experience sexual violence and receive social support are reported to have higher self-esteem, positively impacting their health (Shahali et al., 2010). In Golding, Wilsnack, and Cooper's (2002) study, social support was shown as having a protective effect against psychological disorders in victims of sexual violence, especially because victims seem to get less support than non-victims (Mason et al., 2009).

In social support networks, advantages take forms of emotional, relational, material, and informative support, strong ties, and opportunities to be supporters (Netto et $a l ., 2017)$. The lack of a social support system can have negative consequences for psychological health, so that with social support, negative psychological effects on victims can be minimized (Panaghi et al., 2013).

\section{CONCLUSION}

Previous studies refer to social movements as fairly structured collective actions that aim to change political, social, or cultural conditions detrimental to most groups. One significant and popular social movement is the Second Wave Feminist Movement that focuses on gender equality, including violence against women caused by society's patriarchal culture.

Advances in technology during the last few decades have brought changes to social movements, that is, from offline action only to virtual action online and in the real world. The online world effectively executes and spreads the movement's agenda because it collapses distance and time to connect people around the world.

To achieve its goals, an online social movement needs to sustain communication and strengthen bonds among individuals. By building trust at the CBT level and then continuing to build the KBT level among people will help online social movements collect numbers of people to execute protests and campaigns as collective action.

Trust-building in a movement focused on violence against women can also positively impact women victims of sexual violence. When trust among social movement members is at IBT level, they can comfortably share their stories and seek online support because trust is growing stronger between members. Victims of sexual violence can trust the group because of the social movement's characteristic as a collective identity, with similar restlessness about certain issues; thus, victims can feel safe sharing their stories and seeking social support without the fear of victim blaming and social judging. Such social support can also help victims' overall psychological health.

In conclusion, trust-building is an important element in online social movements, especially those focused on violence against women and also for victims of sexual violence seeking social support. Trust increases comfort and security values in relationships, encourages influential openness, and facilitates substantive information exchange.

\section{FUTURE RESEARCH}

After this literature review on violence against women, further research should examine trust-building and social support in online social movements. Research should be continued on the working thesis that focus on trust-building and social support in movements on social media, such as Facebook, Twitter, and Instagram, is crucial. The goal is to delve deeper into how social media can build trust to create and sustain social movements so that they become positive, safe spaces for their members to seek the positive support they lack and then to pass social support forward.

\section{REFERENCES}

[1] Andalibi, N., Ozturk, P. and Forte, A. 2017 Sensitive self-disclosure, responses, and social support on Instagram: the case of \#Depression. ACM, Portland. 
[2] Barnett, M., Anderson, J., Houle, M., Higginbotham, T. and Gatling, A. 2010 The process of trust building Between university researchers and urban school personnel. SagePublishing.

[3] Blanchard, A. L., Welbourne, J. L. and Boughton, M. D. (2011). 'A model of online trust: the mediating role of norms and sense of virtual community'. Information, Communication and Society, 14(1), pp. 76-106. DOI: https://doi.org/10.1080/13691181003739633.

[4] Carty, V. 2018 Social movements and new technology. Routledge, New York.

[5] Castelfranchi, C. and Falcone, R. 2010 Trust theory: A socio-cognitive and computational model. John Wiley \& Sons, Chichester.

[6] Chiu, C., Hsu, M. H. and Wang, E. T. G. (2006). 'Understanding knowledge sharing in virtual communities: an integration of social capital and social cognitive theories'. Decision Support Systems, 42(3), pp. 1872-1888. DOI: https://doi.org/10.1016/j.dss.2006.04.001.

[7] Cornet, V. P., Cafaro, F., Hall Natalie, K. and Brady, E. 2017 How image-based social media websites support social movements. ACM, Denver.

[8] Diani, M. (1992). 'The concept of social movement'. The Sociological Review, 40(1), pp. 1-25. DOI: https://doi.org/10.1111/j.1467954X.1992.tb02943.x.

[9] Doeneka, M. M. (1972). 'The women's liberation movement and identity change: an urban pilot study'. Dissertations and Theses, Paper 957.

[10] Erol, R. Y. 2008 Social support (perceived VS received) as the moderator Between the relationship of stress and health outcomes: importance of locus of control. Middle East Technical University.

[11] Evans, M. S. (2015). 'Women's liberation: seeing the revolution clearly'. Feminist Studies, 41(1), pp. 138-149.

DOI: https://doi.org/10.15767/feministstudies.41.1.138.

[12] Falcone, R., Sigh, M. and Tan, Y.H. 2001 Trust in cyber-societies: integrating the human and artificial perspectives. Springer-Verlag, Berlin Heidelberg, Germany.

[13] Giele, J. Z. 1988 Gender and sex roles. On Handbook of Sociology 291. Sage Publications, Inc, $\mathrm{CA}$.

[14] Gwebu, K. L., Wang, J. and Troutt, M. D. (2007). 'A conceptual framework for understanding trust building and maintenance in virtual organizations'. Journal of Information Technology Theory and Application (JITTA), 9(1), pp. 43-63.

[15] Heise, L., Ellsberg, M. and Gottmoeller, M. (2002). 'A global overview of gender-based violence'. International Journal of Gynaecology and Obstetrics, 78, pp. S5-S14. DOI: https://doi.org/10.1016/S0020-7292(02)00038-3. PubMed: 12429433.

[16]1Hill, C. A. and O'hara, E. A. (2006). 'A cognitive theory of trust'. Washington University Law Review, 84(7).

[17] Jarvenpaa, S. L., Knoll, K. and Leidner, D. E. (1998) (Spring 1998). 'Is anybody out there? Antecedents of trust in global virtual teams'. Journal of Management Information Systems. ABI/INFORM Global pg. M.E. Sharpe, Incorporated, 14(4), p. 4. DOI: https://doi.org/10.1080/07421222.1998.11518185.

[18] Kappler, K. E. 2012 Living with paradoxes: victims of sexual violence and their conduct of everyday life. VS Verlag für Sozialwissenschaften, Germany.

[19] Kim, H. (2014) (2014). 'Enacted social support on social support and subjective well-being'. International Journal of Communication, 8, pp. 2340-2342.

[20] Lauer, T. W. and Deng, X. (2007). 'Building online trust Through privacy practices'. International Journal of Information Security, 6(5), pp. 323-331. DOI: https://doi.org/10.1007/s10207-007-0028-8.

[21] Lewicki, R. J. and Bunker, B. B. 1996. 'Developing and maintaining trust in working relationships', In RM Kramer \& TR Tyler (Eds.), Trust in organizations: frontiers of theory and research. Sage Publications, CA (114-139).

[22] Li, S., Coduto, K. D. and Morr, L. (2019). 'Communicating social support online: the roles of emotional disclosures and gender cues in support provision'. Telematics and Informatics, 39, pp. 92 100.

DOI: https://doi.org/10.1016/j.tele.2019.02.004.

[23] Lopes, A. R. 2014 The impact of Social media on social movements: the new opportunity mobilizing structure. Creighton University, NE.

[24] Mason, G. E., Ullman, S., Long, S. E., Long, L. and Starzynski, L. (2009). 'Social support and risk of sexual assault revictimization'. Journal of Community Psychology, 37(1), pp. 58-72. DOI: https://doi.org/10.1002/jcop.20270. 
[25] McAdam, D. 1982 Political process and the development of Black insurgency (1930-1970). University of Chicago Press, Chicago.

[26] McAdam, D., McCarthy, D. J. and Zald, M. N. 1988 "Social Movement" on handbook of sociology 695. Sage Publications, Inc, CA.

[27] McKnight, D. H. and Chervany, N. L. 1996 The meaning of trust. University of Minnesota, Minneapolis.

[28] Netto, LdA., Moura, M. A. V., Queiroz, A. B. A., Leite, F. M. C. and Silva, G. Fe (2017). 'Isolation of women in situation of violence by intimate partner: a social network condition'. Escola Anna Nery - Revista de Enfermagem. Escola Anna Nery, 21(1). DOI: https://doi.org/10.5935/1414$\underline{8145.20170007 .}$.

[29] Panaghi, L., Ahmadabadi, Z., Ghahari, S. and Mohammadi, S. (2013). 'Social Support, Coping Mechanisms on Mental Health of Women Suffering from Spouse Abuse'. PCP, 1(1), pp. 915 .

[30] Pandhe, S. (1988). 'Women's studies and women's movement'. Economic and Political Weekly, 23(40), pp. 2049-2050.

[31] Papadopoulos, Konstantinos \& Papakonstantinou, Doxa \& Koutsoklenis, Athanasios \& Koustriava, Eleni \& Kouderi, Vasiliki. (2014). Social Support, Social Networks, and Happiness of Individuals with Visual Impairments. Rehabilitation Counseling Bulletin. Sagepub.

[32] Papakonstantinou, D. and Papadopoulos, K. (2009) (juil. 2009). 'Social support in the workplace for working-age adults with visual impairments'. Journal of Visual Impairment and Blindness. ProQuest, 103(7), p. 393-402. DOI: https://doi.org/10.1177/0145482X0910300703.

[33] Pournaras, E. and Lazakidou, A. (2008). “"Trust and innovativeness in virtual organizations." International Journal of Business Innovation and Research'. Inderscience Enterprises Ltd, 2(3), pp. 262-274.

[34] Rico, N. and United Nations 1997 Gender-based violence: A human rights issue. United Nations, Santiago, Chile.

[35] Ryan, B. 1992 Feminism and the women's movement: dynamics of change in social movement ideology, and activism. Routledge, New York.

[36] Sen, P. (1998). 'Development practice and violence against women’ Gender and Development, 6(3), pp. 7-16. DOI: https://doi.org/10.1080/741922827. PubMed: 12294415.

[37] Shahali, S., Riazi, H., Alaei, S., Emamhadi, M. and Salmeney, F. (2010). 'Preceived social support and self-esteem in sexual violence victims'. Medical Journal of the Islamic Republic of Iran, 33(19).

[38] Shangapour, I.Soran. Hosseini, Seidawan (2011). Cyber Social Networks and Social Movements. Global Journal of Human Social Science. 'Hashemnejad, Hashem', 11(1). Global Journal Inc.

[39] Taylor, V. (1999). 'Gender and social movements: gender processes in women's self-help movements'. Gender and Society, 13(1), pp. 8-33. DOI:

https://doi.org/10.1177/089124399013001002.

[40] Tilly, C. 2004. Paradigm Publishers, London.

[41] Utekhin, I. (2017). 'Small data first: pictures from Instagram as an ethnographic source'. Russian Journal of Communication, 9(2), pp. 185-200. DOI:

https://doi.org/10.1080/19409419.2017.1327328.

[42] Walby, S. 1990 Theorizing patriarchy. Basil Blackwell, Cambridge.

[43] Wang, J., Qiao, K. and Zhang, Z. (2018). 'Trust evaluation Basen on evidence theory in online social networks'. International Journal of Distributed Sensor Networks. SagePublishing.

[44] Yang, F., Zhong, B., Kumar, A., Chow, S.-M. and Ouyang, A. (2018). 'Exchanging social support online: A longitudinal social network analysis of irritable bowel Syndrome patients' interactions on a Health Forum'. Journalism and Mass Communication Quarterly, 95(4), pp. 1033-1057. Sagepub. DOI: https://doi.org/10.1177/1077699017729815.

[45] Yang, X., Li, G. and Huang, S. (2016). 'Perceived online community support, member relations, and commitment: differences between posters and lurkers'. Information \& Management.

[46] Ybarra, M. L., Mitchell, K. J., Palmer, N. A. and Reisner, S. L. (2014). Online social support as a buffer against online and offline peer and sexual victimization among U.S. LGBT and non-LGBT youth. 'Ybarra, Michele \& Mitchell'. Child Abuse and Neglect, 39.

[47] Yeager, J. 2012 Survivors online: A Nethnographic analysis of the emerging role played by the Internet as A source of support for survivors of sexual violence. University of East Londo40-70545-1_14 